\title{
Influence of Gabapentin and Atorvastatin, or its Association, in Mechanical Hyperalgesia and Motor Function Assessed on Crushing Nerve Injury Model
}

\author{
Roberto H Benedetti ${ }^{1}$, Ana C Heymanns ${ }^{1,2}$, Daiana Salm ${ }^{1,2}$, Michele C Michels ${ }^{1}$, Verônica V \\ Horewicz $^{1,2}$, Franciane Bobinski ${ }^{1,2}$, Daniel F Martins ${ }^{1,2}$ and Anna P Piovezan ${ }^{1,2 *}$ \\ ${ }^{1}$ Programa de Pós-graduação em Ciências da Saúde - Universidade do Sul de Santa Catarina (UNISUL), Brasil \\ ${ }^{2}$ Laboratório de Neurociência Experimental (LaNex)-UNISUL, Brasil
}

*Corresponding author: Anna Paula Piovezan, Programa de Pós-graduação em Ciências da Saúde - Universidade do Sul de Santa Catarina (UNISUL), Laboratório de Neurociência Experimental (LaNex)-UNISUL, Endereço: Avenida Pedra Branca, 25, Palhoça, SC, Brazil

\begin{abstract}
ARTICLE INFO
Received: November 24, 2021

Published: 暭ecember 02, 2021

Citation: Roberto H Benedetti, Ana C Heymanns, Daiana Salm, Michele C Michels, Anna P Piovezan, et al., Influence of Gabapentin and Atorvastatin, or its Association, in Mechanical Hyperalgesia and Motor Function Assessed on Crushing Nerve Injury Model. Biomed J Sci \& Tech Res 40(2)-2021. BJSTR. MS.ID.006436.

Keywords: Gabapentin; Atorvastatin; Nervous injury; Neuropathic Pain; Neurotrophins

ABSTRACT

Nerve lesions causes hyperalgesia and loss of motor function. Gabapentin (GABAP) is used in this condition for pain relief, while atorvastatin (ATORV) has demonstrated neuroprotective effects in preclinical studies. We have investigated the influence of GABAP and ATORV on nerve injury. Mice (25-35 g) were subjected to partial ligation of the sciatic nerve. Influence of the drugs on hyperalgesia and grip force was assessed before injury, 7, 14 and 21 days thereafter. Data evaluated by 1 or 2-way ANOVA (P < $0.05)$. GABAP ( $26.67 \pm 4.21 \%$ of response) and ATORV (36.67 $\pm 10.85 \%$ of response), alone or in combination, reduced hyperalgesia (vehicle: $76.00 \pm 11.66 \%$ of response); there was an important effect for the association of these drugs on the grip force. The two agents augmented levels of brain derived neurotrophic factor, BDNF, (vehicle: $105.30 \pm 12.53 \mathrm{pg} / \mathrm{mg}$ of protein; GABAP: $34.92 \pm 5.92 \mathrm{pg} / \mathrm{mg}$ of protein; ATORV: $33.77 \pm 4.20 \mathrm{pg} / \mathrm{mg}$ of protein) and insulin-like growth factor-1, IGF-1, (vehicle: 399.60 $\pm 61.30 \mathrm{pg} / \mathrm{mg}$ of protein; GABAP: $388.30 \pm 38.57 \mathrm{pg} / \mathrm{mg}$ of protein; ATORV: $306.50 \pm$ $16.72 \mathrm{pg} / \mathrm{mg}$ of protein). Association of these substances of different pharmacological classes, may bring benefits on hyperalgesia and motor function associated with nerve lesions.
\end{abstract}

Abbreviations: CNS: Central Nervous System; IL: Interleukins; SC: Schwann Cells; BDNF: Brain-Derived Neurotrophic Factor; IGF-1: Insulin-like Growth Factor-1

\section{Introduction}

Peripheral nerve lesions are frequently observed in the medical clinic and are a global health problem, which results in functional deficits in approximately $2.8 \%$ of all trauma patients1 [1] and are the main reason for absenteeism in Brazil [2]. These patients suffer from muscle weakness, loss of touch sensation, and increased likelihood of developing neurotrophic ulcers. In most cases surgical repair of the injured peripheral nerve is necessary for functional recovery and, in the United States, this represents an annual expenditure of $\$ 7$ billion [3]. The main consequences of nerve damage are sensory changes, including neuropathic pain, as well as functional loss related to motor changes. Neuropathic pain leads to 
common symptoms such as pain in shock or burning, tingling and altered sensations [4,5], and its neurobiological mechanism is quite different from that observed in acute pain, been related to central and peripheral sensitization mechanisms, from which the sensory neurons are sensitized by different compounds and present a decrease in their activation threshold for the nontoxic stimuli [6].

These sensitizing compounds are produced by different cells, both centrally and locally, leading to a paradigm shift in the understanding of neuropathic pain, which has been based on the perception that neurons are not the only type of cell involved in the etiology of this condition. Thus, immune cells such as macrophages, neutrophils and lymphocytes, as well as glial cells such as microglia, astrocytes and endothelial cells, contribute to sensitization in pain pathways, both in the periphery and Central Nervous System (CNS) [7]. Inflammation also contributes to the painful phenomena during the neuropathy, being able to generate the phenomena of allodynia and hyperalgesia; allodynia being the pain that arises after mild stimuli that do not usually cause pain, whereas hyperalgesia refers to the intensification of pain before a painful stimulus [8,9]. In this context, pro-inflammatory or anti-inflammatory cytokines, as well as neurotrophic factors exert influence on painful phenomena and nerve regeneration, which in turn influence the motor capacity of the affected limb. Among Interleukins (IL), IL-10 is an antiinflammatory cytokine that can inhibit the production of other proinflammatory cytokines, and its expression is increased in the distal portion of the sciatic nerve seven days after crushing $[10,11]$.

Sciatic nerve crushing model is a model of axonotmosis, produced by the application of a compressive force to a given nerve, in which the myelin sheath and axons are interrupted, but the basal lamina of Schwann Cells (SC) remains intact [12]. The fibers distal to the lesion undergo degeneration 48 to $96 \mathrm{~h}$ after nerve transection, through a process known as Wallerian Degeneration, the macrophages enter the endoneurium to remove cellular debris, and recovery occurs when the axons send growth cones down from the basal lamina tubes originally preserved toward the final organ $[13,14]$. In this type of model, evaluations of histomorphometric and functional parameters (muscle contraction force) as well as sensory parameters (allodynia and mechanical hyperalgesia) are common [15]. These aspects may be influenced by factors such as Brain-Derived Neurotrophic Factor (BDNF) [16], and Insulin-like Growth Factor-1 (IGF-1) [17], which contribute to nerve regeneration by having functions such as cell-cell adhesion, cytoskeletal reorganization, neurite growth, synaptic plasticity, neuronal survival and neurogenesis, among others [18].

The use of gabapentin (GABAP) to treat painful conditions associated with nerve damage is a consensus in clinical practice, and it has been shown that the drug has improved aspects of nerve regeneration in an animal model of crushing followed by stretching in rats [19]. On the other hand, atorvastatin (ATORV) also promoted neuroprotection in different animal models [20]. Despite this, the possible benefit of the association of these two drugs in different outcomes associated with nerve injury by crushing in mice has not been investigated in preclinical studies. In view of this, the objective of the present study was to evaluate the possible influence of the treatment with GABAP and ATORV, alone or in association, on different aspects observed in a sciatic nerve crush model in mice.

\section{Material and Methods}

\section{Animals}

All experiments were conducted using male Swiss mice (25-35 g), housed at $22 \pm 2^{\circ} \mathrm{C}$, under a $12 \mathrm{hrs}$ light $/ 12 \mathrm{hrs}$ dark cycle (lights on at 6:00 a.m.) and with free access to food and water. Mice were acclimated to the laboratory for at least $1 \mathrm{~h}$ before the tests that were carried out between 8:00 and 12:00. Animals were used only once throughout the experiments. All animal care and experimental procedures were carried out in accordance with the National Institutes of Health Animal Care Guidelines (NIH publications No. 80-23) and were approved by the Ethics Committee for Animal Use (CEUA)-UNISUL, under protocol number 16.026.5.01.IV. The number of animals and intensity of noxious stimuli used were the minimum necessary to demonstrate the consistent effects of treatments. Experimenters were blinded to treatment conditions.

\section{Chemical Reagents}

GABAP (1-[Aminomethyl]-cyclohexaneacetic acid) and caffeine (1,3,7-trimethylxanthine) were purchased by Sigma Chemicals Co. (St Louis, MO, U.S.A.) and were dissolved in sterile saline solution $(0.9 \%)$, immediately before the experiments. Atrovastatin was purchased by Medley (São Paulo, SP, Brazil) and dissolves as GABAP.

\section{Crushing-Induced Nerve Injury}

Mice were kept anesthetized by the inhalation of $2 \%$ isoflurane plus $100 \%$ oxygen. To obtain nerve injury, the sciatic nerve was located through a $2 \mathrm{~cm}$ long rectilinear cutaneous incision on the lateral side of the thigh, from the major trochanter to the knee. After exposure, the nerve was crushed in an area of $5 \mathrm{~mm}$ in length proximal to its trifurcation, using a clamp specially made for this purpose, calibrated for an approximate static load of $5.0 \mathrm{~g}$. After this, the nerve was reattached to its bed of origin and the surgical wound was closed by planes with isolated 5-0 gauge nylon stitches (Ethicon, Edimburg, UK). In the control group, the nerve was exposed but not crushed (sham group).

\section{Drug Infusions}

From days 2 to 21 after crushing of the nerve animals were treated with GABAP $(10,30$ and $100 \mathrm{mg} / \mathrm{kg}$, intragastric [i.g]), ATORV (3 or $10 \mathrm{mg} / \mathrm{kg}$, i.g) or sterile saline $(0.9 \% \mathrm{NaCl}$ solution) 
and mechanical hyperalgesia or grip force were evaluated at different time points after its administration. Sham animals were subjected to the same procedures but were only treated with saline $(0.9 \% \mathrm{NaCl}$ solution).

\section{Study Outlines}

The main outcomes of this study were the mechanical hyperalgesia evaluated by the von Frey test and the grip force. For the evaluation of mechanical hyperalgesia, mice were individually placed in clear Plexiglas boxes $(9 \mathrm{~cm} \times 7 \mathrm{~cm} \times 11 \mathrm{~cm})$ on elevated wire mesh platforms to allow access to the ventral surface of the right hand paw. The withdrawal response frequency was measured following 10 applications (manually, duration of $3 \mathrm{~s}$ each) of a $0.6 \mathrm{~g}$ von Frey hair (VFH, Stoelting, Chicago, IL, USA), responsible to produce a mean withdrawal frequency of about 20\% [21]. Data are presented as the percentage of the animal's response in 10 applications, with $100 \%$ being $10 / 10$ and $0 \%$ being $0 / 10$ responses. A significant increase in the number of responses, at the different periods of times as mentioned above, was interpreted as mechanical hyperalgesia. Indirect evaluation of motor function was performed by the grip force test of the limb subjected to crushing. The apparatus consists of a force transducer connected to a small metallic support, from which the difference $(\Delta)$ of the force (in g) that the animal exerted during the holding of this support with the member that suffered the injury was recorded to the member that has not undergone the crushing procedure. The apparatus was calibrated prior to each experiment and the animals were habituated to the experiment room for at least $1 \mathrm{~h}$ prior to the test.

\section{Evaluation of the Effectiveness of the Association of GABAP + ATORV on Hyperalgesia and Motor Function in the Sciatic Nerve Crush Model of Paw Edema}

In order to confirm the antihyperalgesic effect of GABAP in this model, different animals were submitted to the nerve injury procedure as described above and were treated daily between day 2 and day 21 after the sciatic nerve crush procedure with i.e. vehicle (saline solution, $10 \mathrm{ml} / \mathrm{kg}$ ) or GABAP administration at doses of 10,30 and $100 \mathrm{mg} / \mathrm{kg}$ for selection of the dose to be used in this study. These doses of GABAP and observation periods were chosen from a study conducted in our laboratory [22], also considering the minimum time required for the installation of the neuropathic pain process in the model. After chosen better dose of GABAP to be used in this study, the possible benefit of ATORV alone ( $3 \mathrm{mg} / \mathrm{kg}$ ) or in combination with GABAP $(30 \mathrm{mg} / \mathrm{kg}$ ) was investigated at doses of 3 or $10 \mathrm{mg} / \mathrm{kg}$, these doses were selected from previous work [2328]. At days zero (basal), 7, 14 and 21 days after injury, the animals were evaluated in relation to mechanical hyperalgesia and grip force, as previously described.

\section{Comparison of the Levels of Anti-Inflammatory Cytokine (Il-10) and Neurotrophins (BDNF and IGF-1) from the Sciatic Nerve in Animals Under Different Treatments}

The next protocol was carried out to investigate, if possible, changes in the levels of cytokines and neurotrophins in the nerve could be related to an increase of the late hyperalgesia (neuropathic pain) observed in the model, as well as possible influences of the different treatments on these markers. On the 7th day after the induction of the nerve injury by crushing, animals were euthanized and the sciatic nerve was removed by incision. The distal portion of the nerve was homogenized with PBS containing Tween 20 (0.05\%), $0.1 \mathrm{mM}$ phenylmethylsulfonyl fluoride, $0.1 \mathrm{mM}$ benzomethonium chloride, $10 \mathrm{mM}$ EDTA, and $2 \mathrm{ng} / \mathrm{ml}$ aprotinin A. The solution formed was centrifuged at 3,000 x g for $10 \mathrm{~min}$ at $4^{\circ} \mathrm{C}$, and the supernatant was stored at $-80^{\circ} \mathrm{C}$ for a maximum of 2 weeks. Cytokine or neurotrophin levels were determined using specific ELISA kits (R\&D systems) according to the manufacturer's recommendations.

\section{Statistical Analysis}

Results are presented as the mean \pm standard errors of the mean (S.E.M.) for each group. A statistical comparison of the data was performed by two-way ANOVA followed by Bonferroni's test or one-way ANOVA followed by Newman-Keuls's test when appropriated. P-values less than 0.05 were considered to be statistically significant.

\section{Results}

In the present study crushing of the sciatic nerve induced a behavior of mechanical hyperalgesia in relation to the sham group, already observed from the $7^{\text {th }}$ day after the procedure (Figure 1, Panel A). On the other hand, the treatment of animals with GABAP at doses of 30 and $100 \mathrm{mg} / \mathrm{kg}$ (intragastric) promoted an antihyperalgesic effect when compared to the vehicle group. The antihyperalgesic effect of GABAP was observed on the $7^{\text {th }}$ day after the nerve injury (Figure 1, Panel B), remaining until the highest evaluation time used in this study, 21 days after the injury (Figure 1, Panel C). In this last observation period, the percentage of inhibition of the hyperalgesic effect induced by the lesion after treatment with $30 \mathrm{mg} / \mathrm{kg}$ GABAP (12.50 $\pm 5.26 \%$ response) in relation to the vehicle group (65.71 $\pm 8.41 \%$ response) was $81.0 \%$. On the other hand, in the present study GABAP, at doses of 30 and $100 \mathrm{mg} / \mathrm{kg}$, did not influence the effect of reduction of grip strength of the affected limb induced by nerve injury in the periods (Figure 2, Panel A). On the 21st day after sciatic nerve injury (Figure 2, Panel B), the mean values of the right hind paw grip strength difference compared to the left hind paw for the different groups were sham: $0.76 \pm 1.23 \mathrm{~g}$, vehicle: $-5.19 \pm 0.92 \mathrm{~g}$, GABAP $10 \mathrm{mg} / \mathrm{kg}:-4.48 \pm 0,69 \mathrm{~g}$, GABAP 30 $\mathrm{mg} / \mathrm{kg}:-5.01 \pm 2.08 \mathrm{~g}$ and GABAP $100 \mathrm{mg} / \mathrm{kg}:-4.78 \pm 1.00 \mathrm{~g}$. 

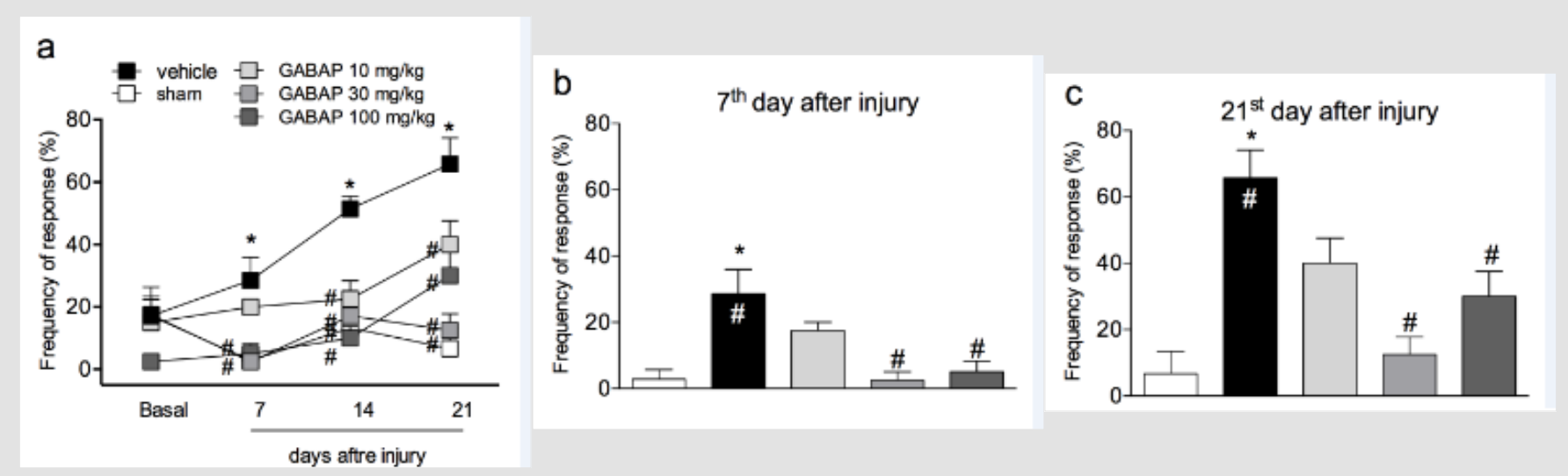

Figure 1: Influence of GABAP on the hyperalgesia observed in the sciatic nerve crush model in mice. Data are expressed as the mean \pm standard error of the mean ( $n=8$ animals). ( $\left.{ }^{*}\right)$ represents the comparison with the sham group; (\#)represents the comparison with the vehicle group. Two-way (Panel a) or One-way ANOVA (Panels b and c), followed by the Dunnets's test; $\mathrm{P} \leq 0.05$.
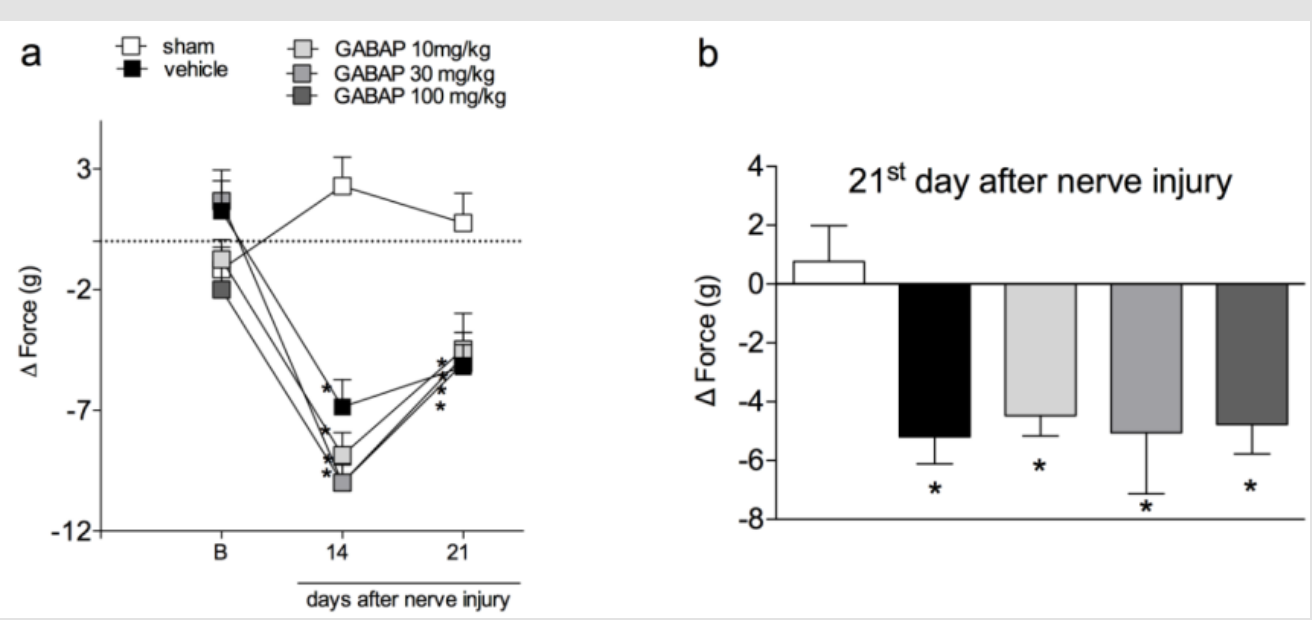

Figure 2: Influence of GABAP on the grip force in mice. Data are expressed as the mean \pm standard error of the mean ( $n=8$ animals). $\left({ }^{*}\right)$ represents the comparison with the sham group. Two-way (Panel a) or One-way ANOVA (Panel b), followed by the Dunnets's test; $\mathrm{P} \leq 0.05$.

When animals were treated with a combination of GABAP (30 mg/kg) with different doses of ATORV ( 3 and $10 \mathrm{mg} / \mathrm{kg}$ ), as shown in (Figure 3, Panel A) there was no difference statistically significant on this antihyperalgesic effect in the tests performed on day 7 (Figure 3, Panel B). On the 21st day after the injury, the percentages of inhibition of the hyperalgesic effect induced by the lesion after the different treatment groups were sham: 8.57 $\pm 4.04 \%$ of response, vehicle $76.00 \pm 11.66 \%$ of response, GABAP $30 \mathrm{mg} / \mathrm{kg}: 26.67 \pm 4.21 \%$ of response, ATORV $3 \mathrm{mg} / \mathrm{kg}: 36.67 \pm$ $10.85 \%$ of response, GABAP+ATORV $3 \mathrm{mg} / \mathrm{kg}: 8.57 \pm 4.04 \%$ and GABAP+ATORV $10 \mathrm{mg} / \mathrm{kg}: 10.00 \pm 4.47 \%$ of response (Figure 3 ,
Panel C). Regarding motor function, ATORV alone ( $3 \mathrm{mg} / \mathrm{kg}$ ), as well as GABAP $30 \mathrm{mg} / \mathrm{kg}$ ) did not influence the effect of reducing the grip force of the affected limb induced by the nerve injury in the evaluated periods (Figure 4, Panel A). On the other hand, as can be seen in Figure 4, on the 21st day after sciatic nerve injury (Panel B) the mean values of the right hind paw grip force compared to the observed at paw of the animals treated with ATORV $3 \mathrm{mg} / \mathrm{kg}+$ GABAP $30 \mathrm{mg} / \mathrm{kg}(-1.29 \pm 1.22 \mathrm{~g})$ or ATORV $10 \mathrm{mg} / \mathrm{kg}+\mathrm{GABAP} 30$ $\mathrm{mg} / \mathrm{kg}(-1.72 \pm 1.74 \mathrm{~g})$ were no longer statistically significant in relation to the sham $(2.00 \pm 1.38 \mathrm{~g})$ and vehicle $(-4.19 \pm 0.57 \mathrm{~g})$ groups. 


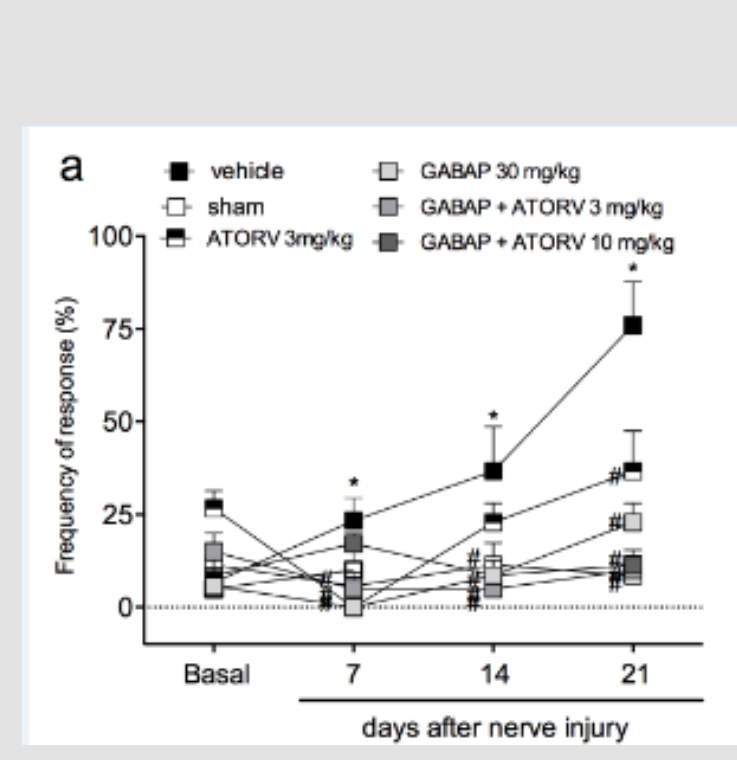

b

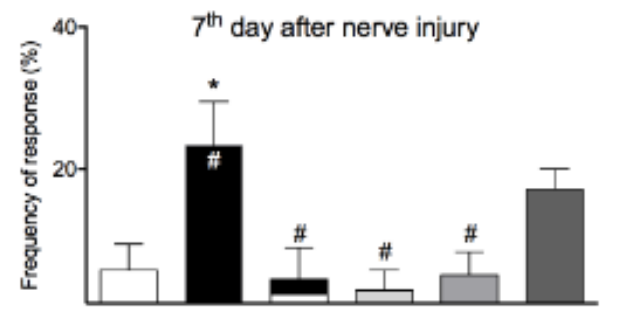

C

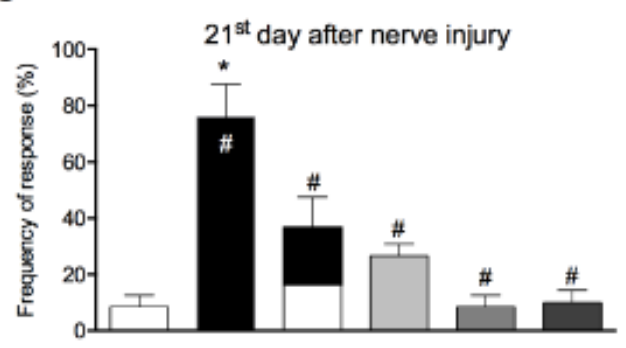

Figure 3: Influence of ATORV, alone or in combination with GABAP on the hyperalgesia observed in the sciatic nerve crush model in mice. Data are expressed as the mean \pm standard error of the mean ( $n=8$ animals). $\left(^{*}\right)$ represents the comparison with the sham group; (\#)represents the comparison with the vehicle group. Two-way (Panel a) or One-way ANOVA (Panels b and c), followed by the Dunnets's test; $\mathrm{P} \leq 0.05$.

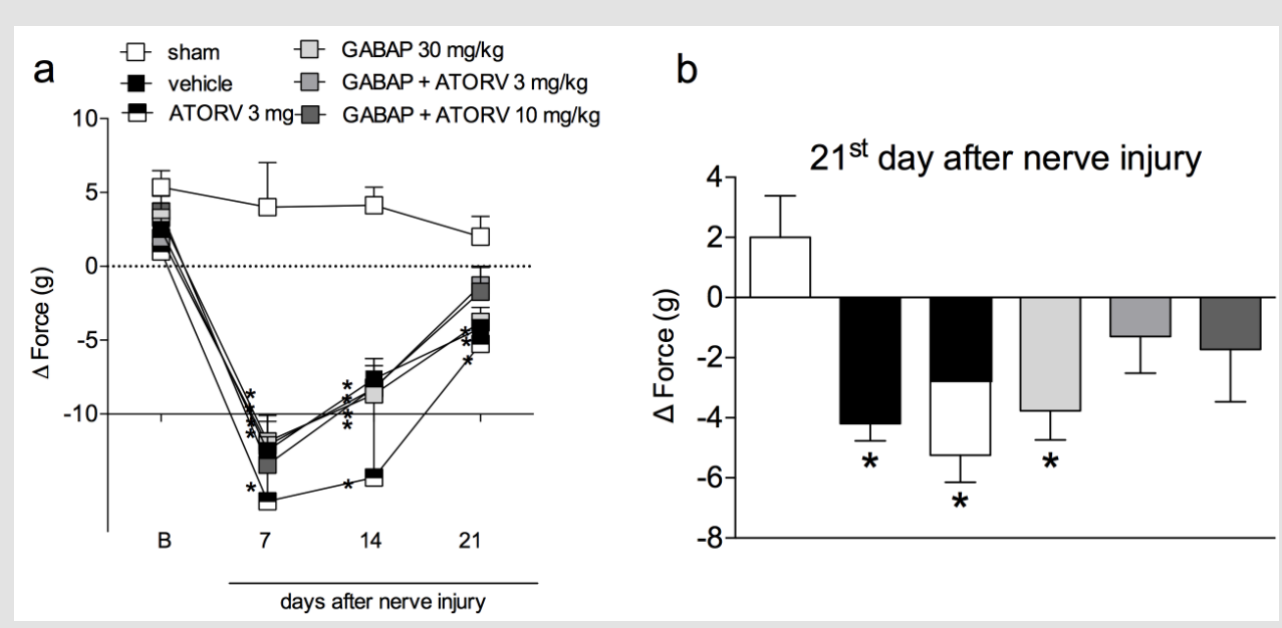

Figure 4: Influence of ATORV, alone or in combination with GABAP on the grip force of the affected limb at different time periods in mice. Data are expressed as the mean \pm standard error of the mean ( $\mathrm{n}=8$ animals). $\left(^{*}\right)$ represents the comparison with the sham group. Two-way (Panel a) or One-way ANOVA (Panel b), followed by the Dunnets's test; $\mathrm{P} \leq 0.05$.

The results shown in Figure 5 demonstrate that the levels of BDNF (105.30 $\pm 12.53 \mathrm{pg} / \mathrm{mg}$ protein) and IGF-1 (399.60 \pm 61.30 $\mathrm{pg} / \mathrm{mg}$ protein) were increased in animal groups $(11.51 \pm 3.69$ $\mathrm{pg} / \mathrm{mg}$ of protein and $25.84 \pm 4.91 \mathrm{pg} / \mathrm{mg}$ of protein, respectively) submitted to the nerve injury by crushing (vehicle groups). In addition, for BDNF (Figure 5, Panel A) treatment with either GABAP (34.92 $\pm 5.92 \mathrm{pg} / \mathrm{mg}$ protein) or ATORV alone $(33.77 \pm 4.20 \mathrm{pg} /$ mg protein), or in combination (30.33 $\pm 5.88 \mathrm{pg} / \mathrm{mg}$ protein), promoted a reduction in the levels of this neurotrophin in relation to the group with nerve damage (data above). Despite this, no statistically significant differences were observed in the mean values of the three treatment groups. On the other hand, in the case of neurotrophin IGF-1 \pm , while the treatment of animals with GABAP (388.30 $\pm 38.57 \mathrm{pg} / \mathrm{mg}$ protein) or ATORV (306.50 \pm 16.72 $\mathrm{pg} / \mathrm{mg}$ of protein) alone did not change in relation to the group that suffered the nerve damage (data above), the association of the two drugs caused a statistically significant reduction in relation to this group (210.40 $\pm 23.92 \mathrm{pg} / \mathrm{mg}$ protein). The percentage inhibition of IGF-1 levels in the group treated with drug combinations was $47.35 \%$ relative to the vehicle group. Finally, no changes in IL-10 levels were observed between any of the study groups (Figure 5, Panel C). 

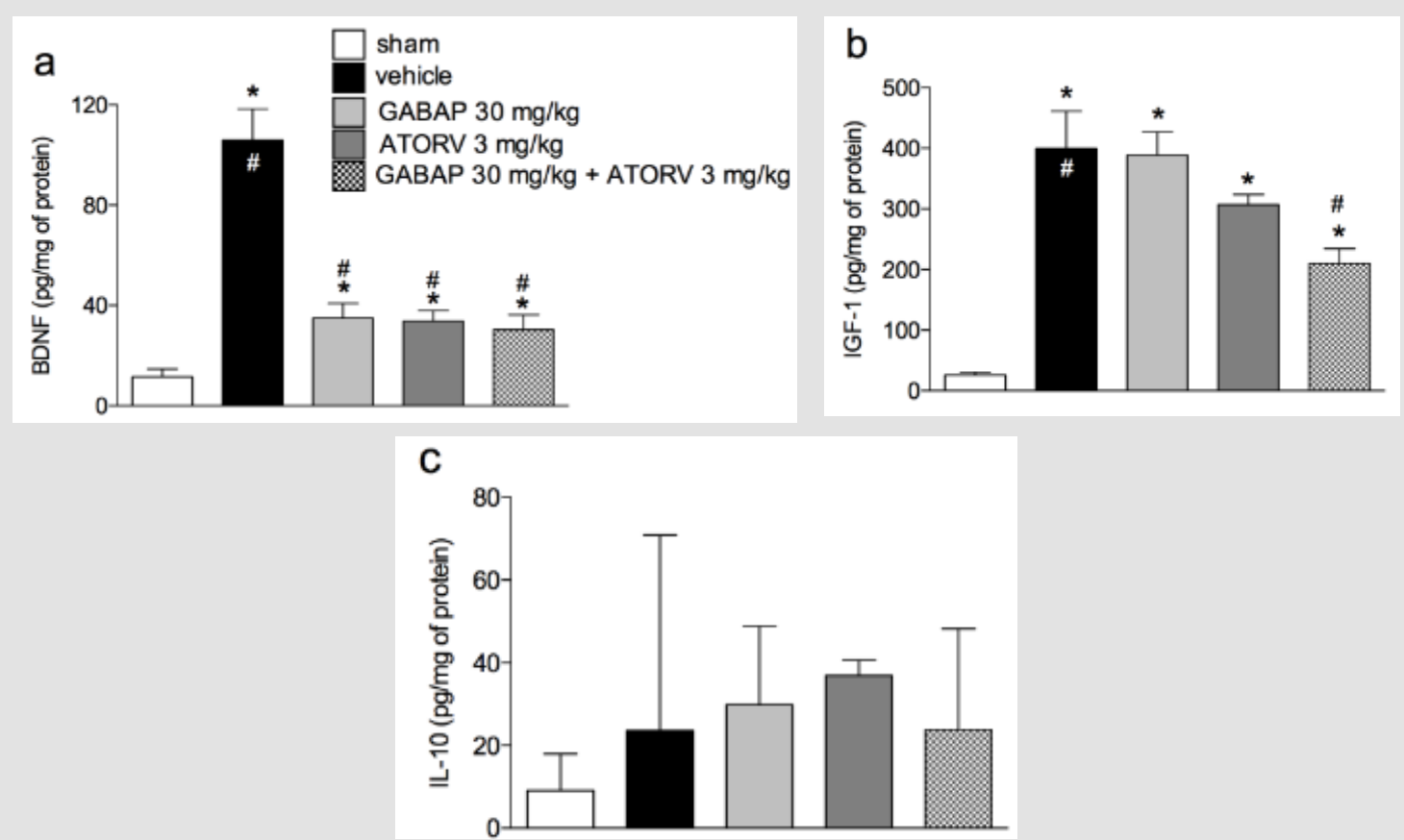

Figure 5: Influence of ATORV, alone or in combination with GABAP on the levels of IL-10, BDNF and IGF-1 in the sciatic nerve. Data for BDNF and IGF-1 are expressed as mean \pm standard error of the mean ( $\mathrm{n}=8$ animals), while for IL-10 are presented as median \pm interquartile range. $\left({ }^{*}\right)$ represents the comparison with the sham group; $(\#)$ represents the comparison with the vehicle group. One-way ANOVA followed by Dunnets's test; $\mathrm{P} \leq 0.05$.

\section{Discussion}

The mechanisms responsible for nerve regeneration and chemical factors are not completely elucidated. Some patients already use some medications of continuous use, including statins in older patients which can be associated to other drugs to relieve pain and prevent neuropathies, such as gabapentinoids. The effects of these drugs and their combinations are under invetigated, justifying the interest in assessing the effect of the association of ATORV with GABAP on parameters of sensory and motor activity in a model of crushing-induced nerve injury. Our data that GABAP was antihyperalgesic on crushing model agree with the literature, since the GABAP also showed reduction of sensorial information in other studies involving thermal hyperalgesia or motor function. Besides of this, it broadens those in the literature, since no records were found for the effects of GABAP on mechanical hyperalgesia and grip strength in mice after sciatic nerve crush injury. In respect to that observed to ATORV in the present study, it was observed that this drug alone promoted antihyperalgesic activity in the model between days 7 and 21 after the injury. The association of ATORV to GABAP did not alter the antihyperalgesic effect of GABAP alone on day 7 , but the increase in antihyperalgesic action on the 21st day was evident.

These findings reinforce the benefit observed with the treatment of animals with ATORV in models where their neuroprotective action has been investigated; in rats with ischemia and multiple sclerosis, the drug protected the neurons from the injury caused by free radicals or limited the secondary damage after spinal cord injury. Regarding the possible mechanisms associated with this effect of gapapentinoids on hyperalgesia and motor recovery, it could involve aspects of nerve regeneration. For ATORV, it is known that statins, particularly ATORV and sinvastatin, have been extensively studied in vivo for their positive neuroprotective effect on different models [25-27]. Thus, a synergistic effect between these two drugs may be suggested, especially if we evaluate our other findings for the association of ATORV to GABAP on the grip strength and BDNF levels, as discussed below. Statins are also related to pleiotropic effects such as anti-inflammatory, antiproliferative, antithrombotic properties and antioxidants.

In the present study, ATORV alone promoted an antihyperalgesic effect, this being another fact that had not yet been reported in the literature. However, since the mean values of hyperalgesia for both ATORV and GABAP, alone, reached values close to the control, it was not possible to observe a possible synergistic effect between both regarding this parameter. However, although in the grip force test the association of ATORV to GABAP did not promote a statistically significant improvement over this parameter, a rather important trend in this sense was noted by the fact that in this group the mean values of loss of grip strength decreased significantly in relation to the GABAP group alone and were very close to the values of the 
control group. The almost significant effect of the association of ATORV with GABAP on motor recovery is striking, since in addition to the actions of these two drugs on nerve protection mentioned above, another action that could add to this would be a possible control of the inflammatory process; this idea is reinforced especially if we consider that the antihyperalgesic effect of both GABAP and ATORV are already observed on the 7th day after the injury, that is, a period in which the inflammatory component is more present.

Studies have shown that the suppression of the release of inflammatory cytokines after experimental injury of the peripheral nerve reflects a positive effect on neurological recovery. Despite this, it should be remembered that some researchers have also reported that statins may be toxic to neurons; in these cases, the toxicity seems to depend on factors such as the structural characteristics and the concentration of the agent employed, as well as the cholesterol content of the affected neural cell. In the present work, a finding that reinforces a possible anti-inflammatory action of the drugs ATORV and GABAP is that the levels of BDNF and IGF-1 in the nerve, increased after the nerve injury by crushing, after treatment with both drugs, alone or in association, have been reduced. The determination of the possible influence of the treatments with these two agents on these two mediators is justified, since studies focusing on the speed of axonal regeneration in the distal part of the nerve have so far focused on three groups of factors, including trophic factors such as IGF-1, IGF-2 and BDNF, as well as the neurotrophic factor derived from glial cell line and cytokines (IL6 and IL-10). It is known that BDNF and IGF-1 are induced in the distal part of the injured peripheral nerves.

Thus, the fact that in the present study, the levels of BDNF in the nerve have reduced after treatment with ATORV and GABAP may suggest that by treatment with them there is a control of the inflammatory process that decreases the need for expression of this factor, even occurring for IGF-1 when treated with the combination of ATORV and GABAP. Confirmation for a possible anti-inflammatory effect of treatments in the present study was not possible since no changes were observed in the levels of IL-10 for any treatment in relation to the control group (sham). This is an anti-inflammatory cytokine that can inhibit the production of other proinflammatory cytokines, and its expression is increased in the distal portion of the sciatic nerve seven days after its crush injury.

\section{Conclusion}

the findings of present study demonstrate the beneficial effect of GABAP or ATORV, alone, on mechanical hyperalgesia in the sciatic nerve crush model in mice. In addition, an important effect for the association of these drugs was observed on the grip strength in this model, and the influence of the two agents on the inflammatory process following the nerve injury may serve as a possible mechanism of action for the observed effects. As a perspective, it is suggested that the association of substances of different pharmacological classes, such as GABAP and ATORV, in products aimed at the treatment of comorbidities associated with nerve lesions can be evaluated in humans, mainly because they are already used in the population that is more neuropathic conditions, and epidemiological studies such as clinical trials may confirm the potential benefit raised here.

\section{Acknowledgment}

This work was supported by grants from Universidade do Sul de Santa Catarina - Programa Unisul de Iniciação Científica (PUIC), Conselho Nacional de Desenvolvimento Científico e Tecnológico (PNPD-CNPq) and Fundação de Amparo à Pesquisa e Inovação do Estado de Santa Catarina (FAPESC, Call 09/2015), Brazil.

\section{References}

1. Ashmawi Ha, Freire Gmg (2016) Peripheral and central sensitization. Rev Dor 17: 31-34.

2. Câmara CC, Araújo CV, DE Sousa Kko, Brito GAC, Vale ML, et al. (2015) Gabapentin attenuates neuropathic pain and improves nerve myelination after chronic sciatic constriction in rats. Neurosci Lett 607: 52-58.

3. Câmara CC, Ramos HF, DA Silva AP, Araújo CV, Gomes AS, et al. (2013) Oral gabapentin treatment accentuates nerve and peripheral inflammatory responses following experimental nerve constriction in Wistar rats. Neurosci Lett 556: 93-98.

4. Castillo Galván ML, Martínez Ruiz FM, DE LA Garza Castro O, Elizondo Omaña Re, Guzmán López S (2014) Study of peripheral nerve injury in trauma patients. Gac Med Mex 150(6): 519-523.

5. Chu LW, Chen JY, Wu PC, Wu BN (2015) Atorvastatin prevents neuroinflammation in chronic constriction injury rats through nuclear NF-B downregulation in the dorsal root ganglion and spinal cord. ACS Chem Neurosci 6(6): 889-898.

6. Cloutier FC, Rouleau DM, Hébert Davies J, Beaumont PH, Beaumont E (2013) Atorvastatin is beneficial for muscle reinnervation after complete sciatic nerve section in rats. J Plast Surg Hand Surg 47(6): 446-450.

7. DE Francesco Lisowitz A, Lindborg JA, Niemi JP, Zigmond RE (2015) The neuroimmunology of degeneration and regeneration in the peripheral nervous system. Neuroscience 302: 174-203.

8. Echeverry S, Shi XQ Yang M, Huang H, Wu Y, et al. (2017) Spinal microglia are required for long-term maintenance of neuropathic pain. Pain 158(9): 1792-1801.

9. Gao S, Zhang ZM, Shen ZL, Gao K, Chang L, et al. (2016) Atorvastatin activates autophagy and promotes neurological function recovery after spinal cord injury. Neural Regen Res 11(6): 977-982.

10. Garraway SM, Huie JR (2016) Spinal Plasticity and Behavior: BDNFInduced Neuromodulation in Uninjured and Injured Spinal Cord. Neural Plast 2016: 9857201.

11. (2013) ISAACS J. Major peripheral nerve injuries. Hand Clin 29: 371-382.

12. Liu W, Lv Y, Ren F (2018) PI3K/Akt Pathway is required for spinal central sensitization in neuropathic pain. Cell Mol Neurobiol 38(3): 747-755.

13. Martins DF, Prado MR, Daruge-Neto E, Batisti AP, Emer AA, et al. (2015) Caffeine prevents antihyperalgesic effect of gabapentin in an animal model of CRPS-I: evidence for the involvement of spinal adenosine A1 receptor. J Peripher Nerv Syst 20(4): 403-409. 
14. Oliveira Júnior JO DE, Portella Junior CSA, Cohen CP (2016) Inflammatory mediators of neuropathic pain. Rev Dor 17: 35-42.

15. Pan HC, Yang DY, Ou YC, Ho SP, Cheng FC, et al. (2010) Neuroprotective effect of atorvastatin in an experimental model of nerve crush injury. Neurosurgery 67(2): 376-389.

16. Sakowski SA, Feldman EL (2012) Insulin-like growth factors in the peripheral nervous system. Endocrinol Metab Clin North Am 41(2): 375-393.

17. Scheib J, Höke A (2013) Advances in peripheral nerve regeneration. Nat Rev Neurol 9(12): 668-676.

18. Shunmugavel A, Martin MM, Khan M, Copay AG, Subach BR, et al. (2013) Simvastatin ameliorates cauda equina compression injury in a rat model of lumbar spinal stenosis. J Neuroimmune Pharmacol 8(1): 274-286.

19. Siqueira Mietto B, Kroner A, Girolami EI, Santos Nogueira E, Zhang J, et al. (2015) Role of IL-10 in Resolution of inflammation and functional recovery after peripheral nerve injury. J Neurosci 35(50): 16431-16442.

20. Sohn HM, Hwang JY, Ryu JH, Kim J, Park S, et al. (2011) Simvastatin treatment improves functional recovery after experimental spinal cord injury by upregulating the expression of BDNF and GDNF. Neurosci Lett 487(3): 255-259.

21. Sohn HM, Hwang JY, Ryu JH, Kim J, Park S, et al. (2017) Simvastatin protects ischemic spinal cord injury from cell death and cytotoxicity

ISSN: 2574-1241

DOI: 10.26717/BJSTR.2021.40.006436

Anna P Piovezan. Biomed J Sci \& Tech Res

(c) (P) This work is licensed under Creative

Submission Link: https://biomedres.us/submit-manuscript.php through decreasing oxidative stress: in vitro primary cultured rat spinal cord model under oxygen and glucose deprivation-reoxygenation conditions. J Orthop Surg Res 12(1): 36

22. Stemkowski PL, Zamponi GW (2014) The tao of IGF-1: insulin-like growth factor receptor activation increases pain by enhancing T-type calcium channel activity. Sci Signal 7(346): pe23.

23. Stump Prnag, Kobayashi R, DE Campos AW (2016) Low back pain. Rev Dor 17: 63-66.

24. Swiger KJ, Manalac RJ, Blumenthal RS, Blaha MJ, Martin SS (2013) Statins and cognition: a systematic review and meta-analysis of short- and longterm cognitive effects. Mayo Clin Proc 88(11): 1213-1221.

25. Wood MD, Kemp SWP, Weber C, Borschel GH, Gordon T (2011) Outcome measures of peripheral nerve regeneration. Ann Anat 193(4): 321-333.

26. Xu L, Zhang Y, Huang Y (2016) Advances in the Treatment of Neuropathic Pain. In: Advances in Experimental Medicine and Biology 904: 117-129.

27. Zheng J, Sun J, Lu X, Zhao P, Li K (2016) BDNF promotes the axonal regrowth after sciatic nerve crush through intrinsic neuronal capability upregulation and distal portion protection. Neurosci Lett 621: 1-8.

28.Zimmermann M (1983) Ethical Guidelines for investigations of experimental pain in conscious animals. Pain 16(2): 109-110.

\begin{tabular}{ll} 
BIOMEDICAL & Assets of Publishing with us \\
RESEARCHES & - Global archiving of articles \\
& - Immediate, unrestricted online access \\
\hline ISSN: 2574-1241 & - Rigorous Peer Review Process \\
&
\end{tabular}

